\title{
Mechanical Properties of a Polyester Fibre Glass Composite
}

\author{
Aramide F. O. ${ }^{1, *}$, Atanda P. O. ${ }^{2}$, Olorunniwo O. E. ${ }^{2}$ \\ ${ }^{1}$ Metallurgical and Materials Engineering Department, Federal University of Technology, Akure, Ondo State, Nigeria \\ ${ }^{2} \mathrm{M}$ aterials Science and Engineering Department, Obafemi Awolowo University, Ile-Ife, Osun State, Nigeria
}

\begin{abstract}
In the present work, mechanical properties of laminates fabricated by Hand lay-up technique using fibre glass (woven-mat) of density $3.6 \mathrm{~N} / \mathrm{m}^{2}$ and general purpose polyester resin was investigated. Fibre glass polyester composite samples were fabricated with different fibre glass volume fractions (A-0.05, B-0.10, C-0.15, C-0.20, D- 0.25 and E- 0.30 ). The materials properties; ultimate tensile strength, Young's modulus of elasticity, elastic strain, and impact strength of the materials were determined through standard tests on standard test samples. It was observed that the various mechanical properties (excluding the impact strength) were improved with increase in fibre glass volume and that the fibre glasspolyester co mposite is characterized by high toughness. It was concluded that the optimu m fibre glass volume fraction for the composite is 0.25 .
\end{abstract}

Keywords Laminates, Fibre Glass (Woven-Mat) Polyester Composite, Toughness

\section{Introduction}

Composite materials are materials that combine two or more materials (a selected filler or reinforcing elements and compatible matrix binder) that have quite different properties that when combined offer properties which are more desirable than the properties of the individual materials. The different materials work together to give the composite unique properties, but with in the composite you can easily see the different materials, they do not dissolve or blend into each other. The key characteristics of composites is the

- Specific strength (the strength to weight ratio $\sigma / \rho$ )

- Specific stiffness or specific modulus (the stiffnessto-weight ratio $\mathrm{E} / \rho$ )

- Tailored material (since co mposites are co mposed of 2 or more "phases", they can be formulated to meet the needs of a specific application with considerable ease)

Fiber-reinforced composites are being increasingly used as alternatives for conventional materials primarily because of their high specific strength, specific stiffness and tailorable properties. In addition the viscoelastic character of composites render them suitable for high performance structural applications like aerospace, marine, automobile, satellites, sports goods, robots, and thermal insulation structures like cryostats for low temperature technology, hydrogen technology tanks, in superconductivity and also in biomed icine for body compatible implants [1, 2, 3 and 4].

* Corresponding author:

fat2003net@yahoo.com (Aramide F.O.)

Published online at http://journal.sapub.org/ijmee

Copyright (C) 2012 Scientific \& Academic Publishing. All Rights Reserved
The above properties are strongly dependent on the factors such as the matrix and fibre material and their volume fractions, the fibre orientation, the applied stress levels and strain rates, as well as the loading conditions and the nature of fibre poly mer interface $[5,6,7]$. Interface is said to be the heart of the composite. The local response of fibre matrix interface within the composite plays an important role in determining the gross mechanical performance [8]. It provides a means of stress transfer from fibre to fibre through the matrix.

In recent times, there has been a remarkable growth in the large-scale production of fibre and/or filler reinforced epoxy matrix co mposites. Because of their high strength-to-weight and stiffness-to-weight ratios, they are extensively used for a wide variety of structural applications as in aerospace, automotive and chemical industries [9]. On account of their good combination of properties, fiber reinforced polymer composites (FRPCs) are used for producing a number of mechanical components such as gears, cams, wheels, brakes, clutches, bearings and seals. Most of these are subjected to tribological loading conditions. The FRPCs exhib it relatively low densities and they can also be tailored for our design requirements by altering the stacking sequences to provide high strength and stiffness in the direction of high loading [10].

The aim of this research is to explore the possibility of reinforcing a polyester resin matrix composite with woven mat fibre glass and to establish the optimum volume fraction.

\section{Materials and Methods}


The materials and equipment used for this project work are: Polyester resin, Methyl Ethyl Ketone Pero xide (catalyst), Cobalt 2\% in solution as accelerator, Fibre Glass, Poly Vinyl Acetone as mould release agent, and Ethanol: This is used to clean off the left over of polyester material from the beaker and other apparatus. Weighing balance: This is used to measure the polyester resin, fibre glass, accelerator and catalyst.

The silicone rubber mould is cleaned and its surface is coated with hard wax to serve as a mould release agent. A weighed gel coat of unsaturated polyester resin containing curing additives (catalyst and accelerator) is then brushed evenly over the mould surface. This is to ensure the formation of a pure resin outer surface to the mould ing. After the gel coat has become stiff, successive alternate layers of weighed fibre glass reinforcement (chopped strand mat in this case) and resin are applied. The fibre glass are fully wetted and impregnated with resin by rollers. A final sealing layer of resin is then applied. When the laminate was fully hardened, it was stripped fro $m$ the mould and trimmed to size using hand file.

Several samples of vary ing fibre content, ranging from A ( $5 \%$ fibre content) to F ( $30 \%$ fibre content) were prepared using the above described method.

\subsection{Tensile Testing}

The tensile tests were performed on INSTRON 1195 at a fixed crosshead speed of $10 \mathrm{~mm} \mathrm{~min}^{-1}$. Samples were prepared according to ASTM D412 and tensile strength of standard and conditioned samples was calculated.

\subsection{Impact Test}

Two samples for each set A, B, C, D, E and F cast using the same method described above. A mould of uniform rectangular cross section was used to prepare Izod samples of uniform thickness.

The impact tests were performed on various sample determine the impact strengths by the "V-notch method using the Hons field Balance Impact Testing Machine. Prior to mounting on the machine, the test sample is notched to a depth of $2 \mathrm{~mm}$ with $\mathrm{v}$-shaped hand file. The notched test sample was then mounted on the impact-testing machine, which is the operated to apply a (constant) impact force on the test sample. The impact strength (the amount of impact energy the specimen absorbed before y ield ing) was then read off the calibrated scale on the impact testing machine.

\section{Results and Discussion}

The results obtained from the tests conducted on various samples was recorded in Table 1., while Figure 1. relates the effect of fibre glass volume fraction on the modulus of elasticity of the system; Figure 2. shows the effect of fib re glass volume fraction on the ultimate tensile strength of the system; Figure 3. depicts effect of fibre glass volume fraction on elastic strain of the system; Figure 4 elucidates effect of fibre glass volume fraction on the average absorbed energy of the system; Figure 5 shows ultimate tensile strength strain curve of the system.

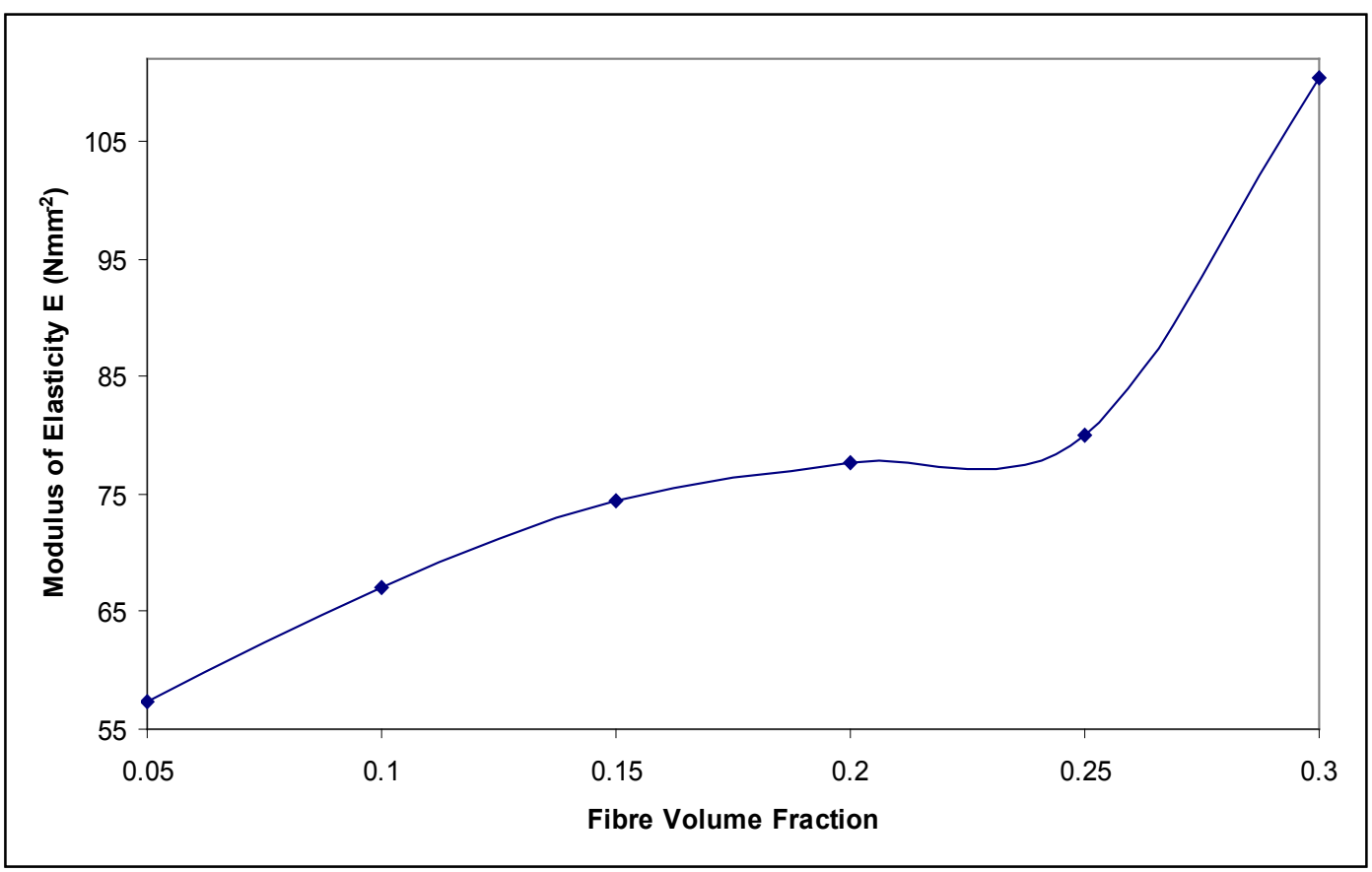

Figure 1. Effect of Fibre Glass Volume Fraction on the Modulus of Elasticity of the System 


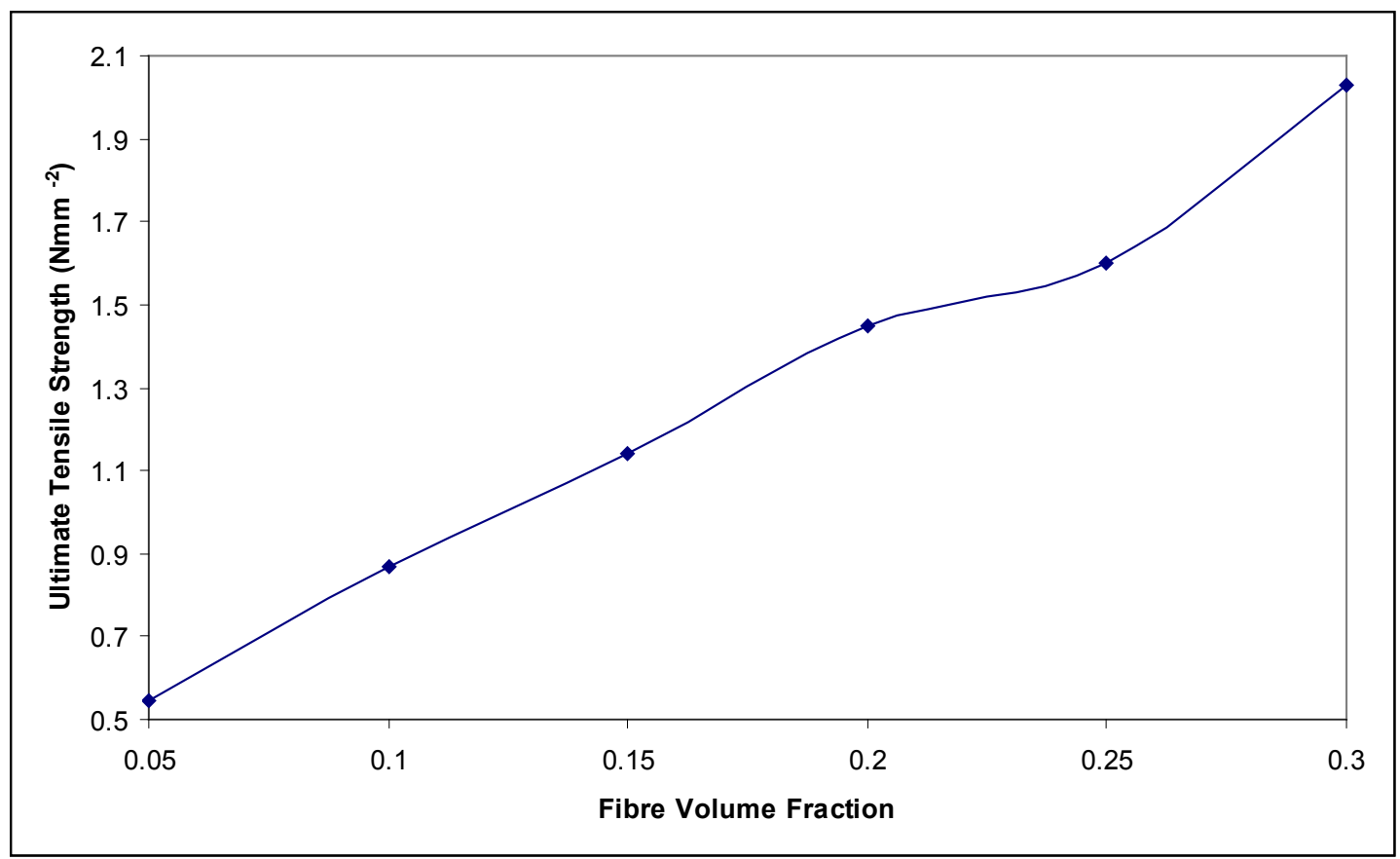

Figure 2. Effect of Fibre Glass Volume Fraction on the Ultimate Tensile Strength of the System

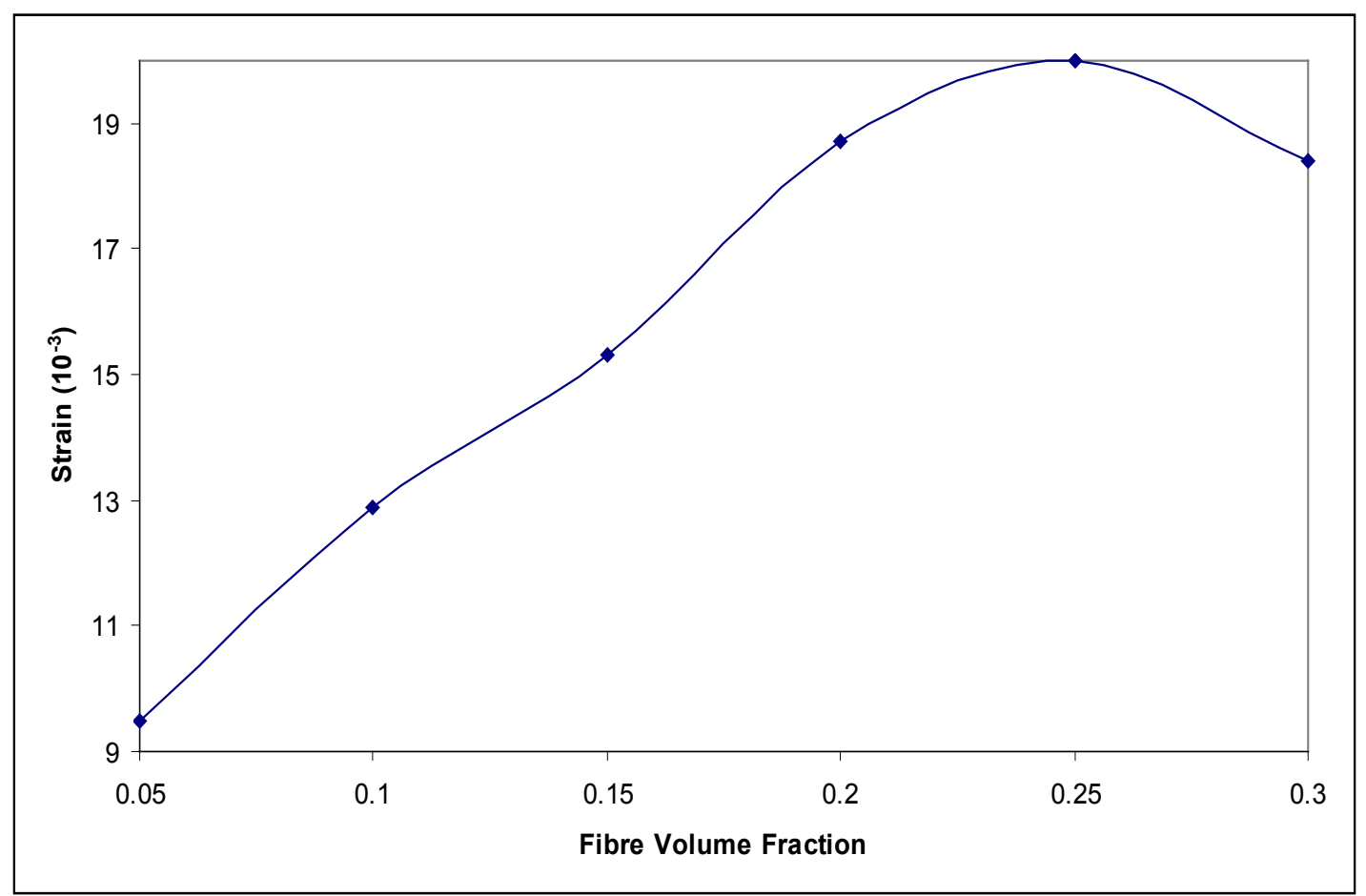

Figure 3. Effect of Fibre Glass Volume Fraction on Strain of the System

Table 1. Mechanical Properties of the Test Samples

\begin{tabular}{|c|c|c|c|c|c|}
\hline Sample Identity & $\begin{array}{c}\text { Fibre Volume } \\
\text { Fraction }\end{array}$ & Strain $\left(10^{-3}\right)$ & $\begin{array}{c}\text { Ultimate Tensile } \\
\text { Strength }\left(\mathrm{Nmm}^{-2}\right)\end{array}$ & $\begin{array}{c}\text { Modulus of } \\
\text { Elasticity E }\left(\mathrm{Nmm}^{-2}\right)\end{array}$ & $\begin{array}{c}\text { Average Absorbed } \\
\text { Energy }(\mathrm{J})\end{array}$ \\
\hline A & 0.05 & 9.5 & 0.545 & 57.36 & 43.875 \\
\hline B & 0.10 & 12.9 & 0.866 & 67.13 & 43.538 \\
\hline C & 0.15 & 15.3 & 1.139 & 74.44 & 42.863 \\
\hline D & 0.20 & 18.7 & 1.451 & 77.63 & 42.525 \\
\hline E & 0.25 & 20.0 & 1.601 & 80.05 & 41.850 \\
\hline F & 0.30 & 18.4 & 2.030 & 110.32 & 41.175 \\
\hline
\end{tabular}


From Figures 1., 2. and 3. it can be seen clearly that the modulus of elasticity, ultimate tensile strength, and elastic strain of the system respectively increases with increase in the increase in fibre glass volume fraction. The greater the modulus, the stiffer the material, or the smaller the elastic strain that results from the application of a given stress [7, 11]. As seen in Figure 1., it reveals that with the increase in fibre glass volume in the composite samples, it becomes stiffer; considering Figure 3. it will be observed that the elastic strain increase with increase in fibre glass volume fraction, it attains the maximum value at around 0.25 fib re glass volume fraction, it there after reduces with further increase in fibre glass volume fraction. Figures 1 and 2 only show only little change (reduction) in modulus of elasticity and UTS respectively at 0.25 fibre glass volume fraction this could be attributed to the fact that glass fibres are characterized by their high strength, good temperature and corrosion resistance, and low price [12].

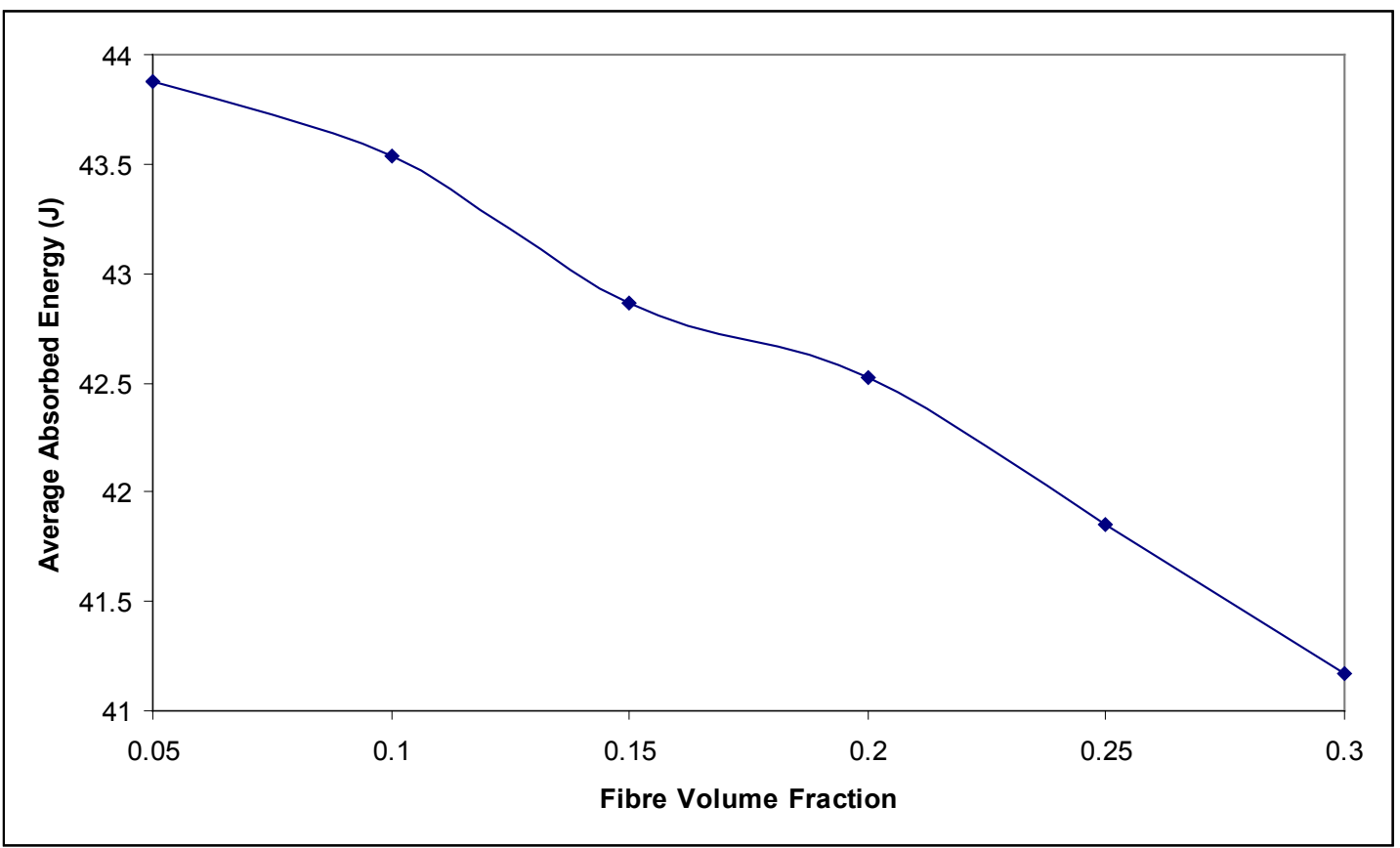

Figure 4. Effect of Fibre Glass Volume Fraction on the Average Absorbed Energy of the System

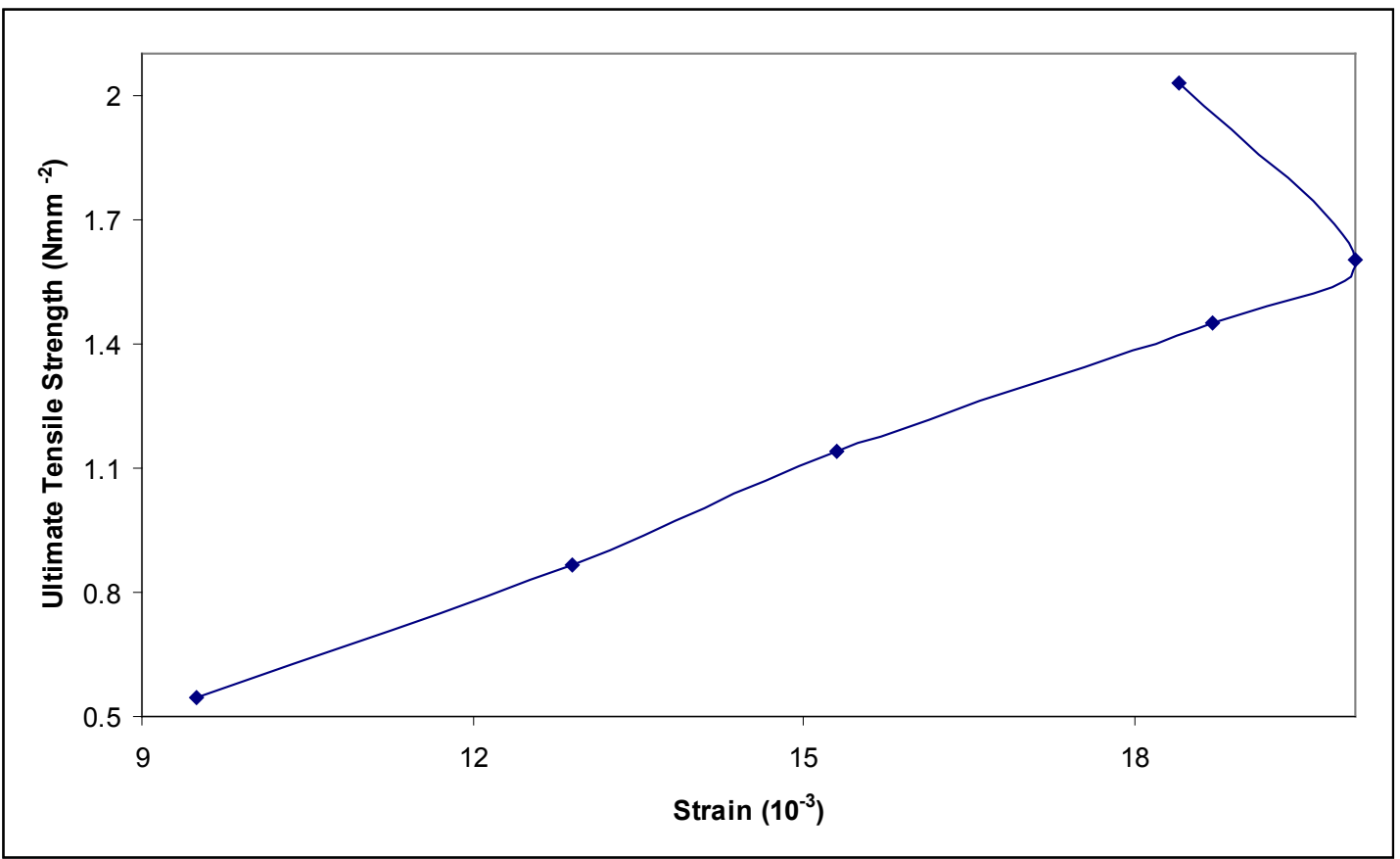

Figure 5. Ultimate Tensile Strength - Strain Curve of the System 
Figure 4. shows that the impact strength of the samples decreases with increase in fibre glass volume fraction; this is expected because glass is know with its poor resistance to impact force.

Observing the Table 1 of data above, it will be seen clearly that there is little change in the absorbed energy, this shows that the fibre glass contributes little to the impact strength of the composite. Glass and other brittle materials have a very low resistance to crack propagation, as there is no mechanis $m$ to cope with the stress concentrations which arise from cracks and flaws. According to fracture mechanics, cracks greater than a critical length will propagate catastrophically under load. In bulk, glass is relatively weak, due to the many cracks which form when it cools. Figures 1., 2., 3. and 5., point to the fact that the composite resulting from the fibre glass- polyester is characterize by high toughness (resistance to crack propagation). In this case, a mechanism for crack stopping exists because of the presence of many fibre / matrix interfaces.

\section{Conclusions}

From the discussion thus far, it can be concluded that:

- ultimate tensile strength of the fibre glass polyester composite increases with increase in the fibre glass volume fraction

- the Young's modulus of elasticity of the composite increases with the fibre glass volume fraction

- the elastic strain of the composite increases with the fibre glass volume fraction up to 0.25 , and then subsequently decreases with further increase in fibre glass volume fraction.

- absorbed energy (impact strength) of the composite samples on the other hand reduces with increase in fibre glass volume fraction.

- generally, fibre glass-polyester is characterize by high toughness (resistance to crack propagation).

\section{ACKNOWLEDGEMENTS}

The authors would like to acknowledge the assistance rendered by $\mathrm{Mr}$ Alo F.I., $\mathrm{Mr}$ Aminu, $\mathrm{Mr}$ Omolayo, $\mathrm{Mr}$ Olaoye and Mr So lanke, (all of the Department of Materials
Science and Engineering, O.A.U., Ile-Ife) during the bench work of this research.

\section{REFERENCES}

[1] Mangalgiri P.D. (1999) Composite materials for aerospace applications. Bulletin of Materials Science;22(3): 657-664

[2] Lynn J.C. (1990) Polymer composite characterization for automotive structural applications. Journal of Composites Technology and Research;12(4):229-231.

[3] Fabian P.E., Rice J.A., Munshi N.A., Humer K. and Weber H.W. (2002) Novel Radiation-Resistant Insulation Systems for Fusion Magnets. Fusion and Engineering Design; 61(1):795-799

[4] Wróbel, G. and Wierzbicki, Ł. (2007) Ultrasonic methods in diagnostics of glass-polyester composites, Journal of Achievements in Materials and Manufacturing Engineering, Vol $20(1-2)$

[5] Habak, E., (1991); Mechanical behaviour of woven glass fibre reinforced composites under impact compression load. Composites 22(2):129-134.

[6] Hsiao, H. M., Daniel, I. M., \& Cordes, R.D. (1999). Strain rate effects on the transverse compressive and Shear behavior of unidirectional composites. Journal of Composite Materials, 33, 1620-1642. http://dx.doi.org/10.1177/0021998 39903301703.

[7] Aramide, F.O., Oladele, I.O. and Folorunso, D.O. (2009); Evaluation of the Effect of Fiber Volume Fraction on the Mechanical Properties of a Polymer Matrix Composite Issue $14,134-141$

[8] Zhou, L.M. (1993); Micromechanical characterization of fibre/matrix interfaces Composites Science and Technology 48(1-4):227-236.

[9] ASM Hand book, 1992, Materials Park, Ohio, USA, ASM International, Volume 18.

[10] Pascoe, M.W., (1973) "Plain and filled plastics materials in bearing: a review.” Tribology, Vol. 6 No. 5, pp. 184-190.

[11] Callister, W.D. (2000).Materials science and Engineering: An Introduction. John Wiley and sons, Inc., New York

[12] Dag Lukkassen and Annette Meidell, (2008); Advanced Materials and Structures and their Fabrication Processes Book manuscript, Narvik University College, HiN, p68. 